\title{
Sell them what they want; give them what they need: managing tensions and competing expectations in live online lecturer development workshops
}

\author{
Martin Compton \\ University College London
}

Keywords: academic development; online; CPD; workshops; compassion; pedagogy of care; modelling; metacognition; COVID-19.

\section{The challenge}

As an academic developer I connect with colleagues on many different levels: as tutor, as kindred spirit, as collaborator, as co-creator and sometimes (albeit often reluctantly) as 'agent' of the institution. There are sensitivities consequent of these diverse relationships and tensions when the needs and wishes of academic staff do not align with institutional priorities (Land, 2001). This can be further complicated when training requests focus on practices that do not align with a developer's professional values, expertise, experience or, most importantly, the research evidence. These tensions were magnified and intensified once the implications of COVID-19 became apparent. A gap in central learning technology support (unusual for a teaching-focussed university in the UK), and the necessary rapid roll-out of new software, only added to the anxiety.

I and close colleagues had extensive experience teaching and assessing online, including running one of the university's only fully online programmes, so we were quick to identify a key issue: the completely understandable, almost intuitive, compulsion amongst colleagues to want to translate conventional teaching practices into online contexts. This was coupled with an assumption at senior leadership level that the core need was technical rather than pedagogic training instead of both of these. For example, many assumed that tools like Microsoft Teams and Zoom should host scheduled lecture slots, and that didactic delivery in live, online sessions was an appropriate approach when campuses closed. Furthermore, but very much part of the same mindset, were the assumptions about how, when and with what students would be accessing both live and 
asynchronous content as part of the 'emergency pivot' online. My conundrum was this: how could we address the real and pressing demands this emergency presented whilst not ignoring what research tells us about the 'when' and 'how' of online learning (Means et al., 2014)? Above all, how could I design support that assuaged anxiety and was also authentic and compassionate, enabling colleagues to support their students with adequate pedagogic, inclusivity and technical awareness?

\section{The response}

A key part of the answer would be in the design of live sessions that sat alongside the selfstudy materials we had created. The live sessions included formally scheduled workshops, 'guest' invites to programme teams, 'lunch and learn' sessions at faculty and departmental level and almost constant one-to-one and small group consultancy reaching an unprecedented number of colleagues. Anxiety amongst teaching colleagues and their managers ranged from mildly perturbed to quite panicky, and a clamour for fundamentals and 'top tips' under a collective 'how to' banner meant there were strong drivers obligating us to support the technical upskilling and help fulfil the biggest perceived need. Above all, was a need to accommodate all this but somehow double up the time when connecting with colleagues to talk about essential pedagogy and learning design.

The live, online sessions that I designed or co-designed therefore had a number of principles that were key to their success:

1. Frame events in ways that address the most pressing anxieties. Most events were built around specific activities (e.g. 'Hosting live teaching in Microsoft Teams'). It would have been counterproductive, arrogant even, to dismiss these wishes and, in fact, the one workshop I did run that foregrounded values in the title ('Compassionate responses to emergency remote teaching') attracted far fewer sign-ups than others.

2. Centre compassion for both colleagues and students. By adopting and referencing a 'pedagogy of kindness' (Denial, 2020), every session included provocations, questions, data and narrative accounts that pushed thinking and dialogue towards rationales for not losing sight of existing personal, professional 
and institutional values of inclusivity. Opportunities for connecting on a human level were central to the design.

\section{Model practice for higher impact rather than taking a theoretical focus.}

Examples of this include use of advance organiser techniques such as a selection of opinion-based questions to answer or an interactive graphic to read or explore to foreshadow core concepts. I nudged with at least two friendly reminders about engaging with these short, reflective or cognitive activities ahead of the session. This helped to demonstrate the importance of orienting students to the 'where' and 'how to get there' of a teaching event, as much as orienting to content and modelling this pedagogic approach.

4. Resist the 'click here; click there' training approach. Feedback was almost universally positive across the broad range of events. Where there was criticism, it was in terms of colleagues 'needing' or 'wanting' someone to show them exactly what to do in those live events. Such an ineffective one-size-fits-all model felt inappropriate in those contexts (Compton and Almpanis, 2018), though we did compensate with one-to-one support and self-access guides too.

5. Be open about and rationalise pedagogic approach. 'You may be expecting a "how to" session, but we're approaching it like this because...' and this, in turn, was what we encouraged colleagues to do with their students.

6. Exploit opportunities for meta level discussion throughout. 'Did you notice how I used emojis at the start?' 'How did I encourage colleagues to contribute?' 'What techniques have I used to ...?'.

7. Create and rationalise supportive spaces. No recording; optional camera use; range of ways of participating; nurturing connections.

\section{Recommendations}

The above principles are recommendations for scaled (emergency or otherwise) approaches to development events for teaching staff. Workshops and other live events, like teaching, can be much more effective when there is liberty in the instructional design to include dialogue, share ideas and anxieties, and explore the approaches that are being modelled. Promoting in-session reflection and metacognition is perhaps an obvious technique but is undermined by a tendency towards one-size-fits-all training approaches to 
development, especially in the case of pricey, bespoke, mandatory e-learning packages. My biggest recommendation is more of a plea to university leaders: whether in a crisis or not, do not lose sight of the evidence base and opportunities to realise a more inclusive and compassionate approach to learning, teaching and assessment design. Aligned with this is the need to invest in development, support and training. The most expensive estate and flashiest kit is worth very little if the space and technology use is not supported by appropriate training and evidence-informed thinking.

\section{References}

Compton, M., and Almpanis, T. (2018) 'One size doesn't fit all: rethinking approaches to continuing professional development in technology enhanced learning', Compass: Journal of Learning and Teaching, 11(1). Available at: https://doi.org/10.21100/compass.v11i1.708 (Accessed: 30 July 2021).

Denial, C. (2020) 'A pedagogy of kindness', in Stommel, J., Friend, C. and Morris, S.M. (eds.). Critical digital pedagogy: a collection. Washington, D.C.: Hybrid Pedagogy Inc, pp.212-218.

Land, R. (2001) 'Agency, context and change in academic development', International Journal for Academic Development, 6(1), pp.4-20. Available at: https://doi.org/10.1080/13601440110033715 (Accessed: 30 July 2021).

Means, B., Bakia, M. and Murphy, R. (2014) Learning online: what research tells us about whether, when and how. New York: Routledge.

\section{Author details}

Martin Compton is an Associate Professor working in the central academic development unit (The Arena Centre for research-based education) at UCL. He works closely with the Faculty of Life Science, but his work, which focuses on digital education, is crossinstitutional. He previously worked at the University of Greenwich in the Educational 
Development Unit where he oversaw taught lecturer development courses, digital education initiatives and the university CPD offer. 